\title{
A semântica de frames como instrumento para a análise do discurso discente - marcadores de sucesso em um projeto escolar de dramaturgia
}

\author{
The frames semantics as a tool for analysis of student's speech - indicators success in an academic \\ dramaturgy project
}

\section{Carolina Alves Fonseca}

Neusa Salim Miranda

Universidade Federal de Juiz de Fora - UFJF - Juiz de Fora - Minas Gerais - Brasil

\begin{abstract}
$\longrightarrow$
Resumo:Este trabalho - vinculado ao macroprojeto Práticas de Oralidade e Cidadania (MIRANDA, 2007/FAPEMIG) e ao projeto Lexicográfico FrameNet (www.framenet.icsi.berkeley.edu) em sua linha Frames e Cidadania - define-se como um Estudo de Caso (YIN, 2001) e tem como objetivo a investigação de práticas escolares que contribuem para a promoção da educação da oralidade equacionada a um ambiente interacional favorável ao processo ensino-aprendizagem e à formação cidadã. O cenário investigativo eleito foi uma escola pública da cidade de Juiz de Fora - MG, reconhecida, por gestores e professores, pelo "sucesso" de seus projetos, em especial o projeto de teatro. A base de dados constituiu-se por documentação em áudio (e posterior transcrição) de entrevistas semiestruturadas (LABOV, 2008 [1972]) feitas com os alunos do 60 ano que participam de tal projeto. $\mathrm{O}$ aporte linguístico deste estudo vincula-se à Semântica de Frames (FILLMORE, 1977, 1988, 2007) que fornece a categoria analítica central para a análise dos discursos - o frame. Neste artigo, trazemos resultados parciais acerca da rede de frames evocadas pelo discurso dos discentes, seguindo a metodologia de anotação promovida por uma ferramenta computacional (FrameNetDesktop) do projeto lexicográfico FrameNet. Nas análises parciais começa a ganhar relevo um indicador de sucesso, qual seja a emergência de frames (Criar_texto; Agir_intencionalmente; Formar_relações e outros) em que o aluno se configura como um Ëlemento de Frame com papel ativo na cena mediada pelo professor, o que pode ser o primeiro indicador de sucesso: o Protagonismo Juvenil (COSTA, 2004).
\end{abstract}

Palavras-chave:Semântica de Frames. Rede de Frames. Processo ensinoaprendizagem.

\begin{abstract}
This paper - linked to project Practices Orality and Citizenship (MIRANDA, 2007 /FAPEMIG) and to the lexicographical FrameNet project (www.framenet.icsi.berkeley.edu) in their line Framesand Citizenship - is defined as a study case (Yin, 2001) and aims at the investigation of school practices that contribute to the promotion of education of orality equated to a favorable interactional environment to teaching and learning process and to civic education. The investigative scenario chosen was a public school in the city of Juiz de Fora - MG, recognized, by managers and teachers, by the "success" of their projects, in particular the theater project. The database consisted of documentation in audio (and later transcribed) semi-structured interviews (LABOV, 2008 [1972]) made with students of the 6th year participating in the project. The linguistic contribution of this study is linked to the Semantics of Frames (FILLMORE, 1977, 1988, 2007) that provides a central analytical category for the analysis of discourses - the frame. In this paper, we bring partial results about frames network evoked by the discourse of the students, following the methodology of annotation promoted by a computational tool (FrameNetDesktop) of the lexical project FrameNet. In the partial analysis begins to gain relief an indicator of success, the emergence of frames (Intencionally_create; Intencionally_act; Forming relationships and others) in which the student is configured as a Frame Element with active role in mediated teacher scene, which can be the first indicator of success: youth participation (COSTA, 2004).
\end{abstract}

Keywords: Frames Semantics. Frames Network. Process teaching and learning. 
Entende-se que o significado de uma palavra não pode ser tomado, independentemente, do vasto repositório do conhecimento enciclopédico ou de mundo ao qual está vinculado, pois ele está fundamentado na interação homem-homem e homem-mundo, na interação e no experiencialismo, na experiência social e física. (CHISHMAN; MINGHELLI, 2013, p.135)

\section{Introdução}

Este trabalho insere-se no macroprojeto "Práticas de Oralidade e Cidadania" (MIRANDA, 2007/PNPD/CAPES) que, em sua primeira etapa, delineou, através de um conjunto de estudos de caso já concluídos (MIRANDA, 2007, 2009, 2011; PEREIRA, 2008; LIMA, 2009; PINHEIRO, 2009; BERNARDO, 2011; ALVARENGA, 2012; FONTES, 2012), o "mapa da crise" da sala de aula. Tomada sob a perspectiva da voz discente, a sala de aula se revela nesses estudos, via de regra, como um ambiente largamente conflituoso e hostil ao processo ensino-aprendizagem. Contudo, ainda que em escala muito menor, os relatos discentes também apontam e avaliam, de modo positivo, algumas práticas escolares, assim como o papel dos docentes responsáveis pela mediação de tais práticas. Na fase atual, é nessa direção que nosso macroprojeto configura sua meta investigativa, em busca de indicadores mais claros dessas práticas de sucesso. Assim, no encalço desta meta, o presente estudo em desenvolvimento como dissertação de mestrado (PPG Linguística-UFJF) - elegeu como cenário investigativo uma escola pública da cidade de Juiz de Fora - MG, reconhecida por gestores e professores como uma comunidade "de sucesso". Nesta escola, recortamos como objeto de estudo as práticas veiculadas por um projeto de dramaturgia, buscando encontrar, pela perspectiva discente, os indicadores de seu sucesso.

A escolha metodológica deste estudo de caso envolve, em primeiro lugar, procedimentos de caráter etnográfico, que implicaram um processo de acompanhamento das atividades do projeto de teatro, por 6 meses com total de 15 visitas, anotado em "diário de bordo". No final deste processo, um instrumento investigativo

(entrevistas semiestruturadas [LABOV, 2008] áudio documentadas), foi respondido pelos alunos do $6^{\circ}$ ano que participam do referido projeto.

Para análise do corpus constituído pelas entrevistas, elegemos, como principal categoria analítica, o conceito de frames nos termos firmados pela Semântica de Frames (FILLMORE, 1977, 1988, 2007) e, principalmente, por seu projeto lexicográfico Framenet (www.framenet.icsi.berkeley.edu). Neste recorte teórico-metodológico, situa-se outra meta investigativa deste estudo que consiste em testar a anotação de texto corrido, nos moldes da ferramenta computacional Desktop deste projeto lexicográfico, como um importante instrumento de análise do discurso dos entrevistados. O presente artigo recorta esta meta como seu objeto, dado o relevo que o desenvolvimento de tal experiência metodológica vem merecendo em nosso macroprojeto. Nos termos de Miranda e Bernardo:

Vinculada, em sua gênese, ao discurso de
discentes e docentes, a ideia-chave desta
proposta, no que concerne a sua face
linguística, tem sido evidenciar, através de um
conjunto de Estudos de Caso (...), a eficácia
analítica da Semântica de Frames para a
abordagem dos processos de significação no
discurso. E como a questão educacional que
nos mobiliza não é apenas um pano de fundo
nesta história, o que significa dizer que o
discurso coletado não é apenas um corpus
para pura análise linguística, a proposta que
vimos delineando ganha, neste enquadre,
uma instigante aplicação, qual seja o seu uso
como suporte para a hermenêutica da
realidade social (em nosso caso, educacional)
que emerge na voz dos sujeitos investigados.
(MIRANDA; BERNARDO, 2003, p. 81).

Para tanto, estrutura-se este artigo da seguinte forma: inicialmente, faz-se uma breve revisão da literatura sobre Semântica de Frames, abordando o recurso computacional FrameNet. Em seguida, passa-se à descrição dos passos utilizados para tratamento e anotação dos corpora no Desktop. Após, apresentam-se os principais frames emergentes do discurso discente, apresentando-se uma leitura interpretativa dos primeiros resultados. 


\section{A Semântica de Frames}

A Semântica de Frames originou-se no final da década de 1970 e representa um dos modelos teóricos da Linguística Cognitiva de maior prestígio. De acordo com Chishman e Minghelli, tal modelo corresponde a uma proposta que leva em consideração o significado enciclopédico e a representação do significado da palavra. Nos termos das autoras:

considerando o significado enciclopédico, a referida teoria compromete-se em desvelar o conhecimento associado às palavras, um conhecimento convencional que advém da experiência e da cultura, o qual é representado no nível conceptual e armazenado na memória a longo prazo. (CHISHMAN; MINGHELLI, 2013, p.135)

A ideia central dessa linha de pesquisa é a de que o significado da palavra seja organizado e descrito em frames que, de acordo com Charles Fillmore, trata-se de um sistema de conceitos relacionados de tal modo que, para entender qualquer um deles, é preciso entender toda estrutura na qual se enquadram (FILLMORE, 2009, p. 25). Desse modo, frames são esquematizações de estruturas conceptuais, de crenças, de práticas institucionais que emergem da experiência do dia a dia. Trata-se da representação de uma situação, um objeto ou evento inserida em um background (pano de fundo). Assim configurado, a compreensão do sentido de um item lexical implica conhecer o frame no qual determinado sentido está relacionado. Nas palavras de Chishman e Minghelli:

Segundo a Semântica de Frames, palavras e construções gramaticais são relativizadas a frames de modo que o significado associado a uma palavra ou uma construção gramatical não deve ser entendido independentemente do frame ao qual está relacionado. (CHISHMAN; MINGHELLI, 2013, p.135)

Analisar um texto dentro dessa perspectiva é, portanto, um caminho válido uma vez que os frames oferecem bases conceptuais para os sentidos relacionados a uma palavra (Unidade Lexical) e às outras semanticamente relacionadas a ela. De acordo com Fillmore, Johnson e Petruck (2003), a partir dessa abordagem, pode-se caracterizar todas as categorias de palavras, frases e expressões. Esta é, pois, a justificativa de nossa escolha de tal aporte para a análise do discurso.

Passemos à descrição do principal produto desta teoria semântica, o projeto lexicográfico computacional FrameNet, apresentando também o uso que fazemos dele para a análise do discurso discente.

\subsection{A FrameNet}

A Framenet(https://framenet.icsi.berkeley.edu/fndrupal/) é um recurso lexicográfico que possui como base a Semântica de Frames e apoia-se em evidências extraídas de um corpus. Dela extraem-se, usando procedimentos manuais e automáticos, informações sobre propriedades semânticas e sintáticas de palavras retiradas de corpora - compostos com dados lexicais do Inglês (cerca de 10.000 unidades lexicais, sendo mais de 6.000 anotadas e, aproximadamente, 8.000 relações entre frames exemplificadas em mais de 135.000 sentenças anotadas (RUPPENHOFER et al., 2010).

De acordo com Fillmore, Johnson e Petruck (2003) um dos principais objetivos do projeto é identificar e descrever frames semânticos, analisar as relações presentes entre os evocados e identificar os padrões valenciais das palavras, considerando-se três níveis de anotação: Tipos Sintagmáticos (TS), Funções Gramaticais (FG) e Elementos de Frames $(E F)$, sendo os primeiros níveis sintáticos e o último micropapeis temáticos de natureza semântica.

Como supracitado, frames constituem uma estrutura abstrata de expectativas estruturada de acordo com um contexto motivacional. Há determinadas palavras que servem como uma ponte de acesso a um frame, que fazem com que este seja evocado. Tais palavras são denominadas unidades lexicais (ULs) e são um pareamento entre forma e sentido responsável por evocar um frame.

Normalmente, as ULs evocadores de frames são os verbos. No entanto, outras classes gramaticais 
também têm essa prerrogativa, como preposições no exemplo O cão está NO mato, temos a preposição em evocando o frame Locativo_relação -, advérbios, adjetivos e alguns substantivos. Fillmore et al. (2003) diferencia substantivos nomeadores de coisas da natureza (como ave, sofá) de substantivos eventivos (tribunal e julgamento, por exemplo). Segundo ele, esses têm alta capacidade de evocar frames, enquanto aqueles, não. No domínio das práticas educacionais estudadas neste trabalho, substantivos eventivos, tais como as ULs teatro, peça e outros, comumente evocam frames. Neste caso, os verbos que as acompanham, normalmente fazer, são caracterizados apenas como verbos suporte, não como uma UL.

Com relação à anotação, a FrameNet apresenta dois tipos de modelos, dependendo da forma como as sentenças são encontradas para anotação. O primeiro é o da anotação lexicográfica, que tem por principal objetivo registrar as valências de uma palavra em cada uma de suas sentenças. Escolhe-se uma Unidade Lexical e observa-se sua manifestação em diversas sentenças de vários corpora e faz-se a anotação nas três camadas citadas anteriormente: Elementos de Frame, Função Gramatical e Tipo de Sintagma. O segundo modelo é a anotação em texto corrido, que consiste em selecionar as diversas ULs emergentes dentro de um único corpus de modo a mapear os frames que são evocados por ele.

No presente estudo, utilizamos o segundo modelo de anotação, pois partimos dos textos dos alunos, de modo a identificar quais são os frames emergentes e qual a frequência em que ocorrem. Porém, não anotamos todas as ULs presentes, somente aquelas mais frequentes e que se tornam, portanto, fundamentais para a nossa análise. Desse modo, são anotadas apenas aquelas que nos ajudam a delinear as práticas de sucesso presentes no espaço escolar pesquisado, respondendo à questão investigativa posta neste estudo.

Explicitados os principais conceitos e procedimentos analíticos eleitos neste estudo, passemos, portanto, ao detalhamento das etapas de tratamento e análise do corpus.

\section{Procedimentos analíticos - etapas de tratamento e análise do corpus}

A primeira etapa na constituição do corpus analítico implicou a transcrição das entrevistas e sua etiquetação, de modo a preservar a identidade dos sujeitos investigados. Em seguida, foram elencadas as Unidades Lexicais e Unidades Construcionais mais frequentes no discurso. Para tanto, utilizamos a ferramenta computacional da Linguística de Corpus WordSmith Tools para compor uma Word list. Posteriormente, anotamos no Desktop da FrameNet Brasil (http://www.ufjf.br/framenetbr/) as ULs e UCs evocadas recorrentemente, relacionando-as aos frames descritos pela plataforma.

A especificação das etapas de trabalho no Desktop da Framenet é sintetizada a seguir:

i. Separação automática de cada sentença do corpus pela ferramenta;

ii. Identificação da UL pelo usuário;

iii. Identificada a UL, verifica-se se ela já está incluída em algum frame:

- se sim e o frame já tiver sido traduzido, a própria ferramenta indica quais são o(s) possível(is) frame(s) nos quais a UL se enquadra e o usuário segue a anotação para as camadas de função gramatical e tipo sintagmático dos EFs;

- $\quad$ se não, o usuário deve procurar o frame correspondente, traduzi-lo (caso ele já não tenha sido) e iniciar a etapa de incluir a UL (listar todas as suas possíveis formas linguísticas). Por fim, ocorre a anotação da sentença, com sua UL e seus EF's nas demais camadas.

- caso não haja um frame para determinada UL, deve ser criado. 
Feita tal anotação, passamos à constituição da rede hierárquica de relações entre frames, valendonos da rede constituída pela FrameNet, o framegrapher

(https://framenet.icsi.berkeley.edu/fndrupal/FrameGra pher). Tal rede nos permite mapear, por fim, as experiências perspectivadas pelo discurso discente.

A última etapa consiste em verificar a frequência de ocorrência de tais frames (de suas ULs e EFs mais relevantes) de modo a demarcar as experiências mais convencionalizadas na comunidade em foco. Para tanto, o DesktopFrameNet faz um levantamento, automaticamente, de todos os frames evocados, bem como das ULs evocadoras destes e os EFs presentes, com suas respectivas frequências.

Esse levantamento quantitativo dos dados é relevante para a nossa pesquisa, pois, dentro do paradigma teórico no qual ela se enquadra - a Linguística Cognitiva - as palavras são representantes de categorias (FILLMORE, 1988). Sendo assim, o uso se torna de suma importância, uma vez que a reiteração de determinada UL/UC indica a convencionalização de tal prática, a cristalização de uma vivência.

(CROFT; CRUSE, 2004; TOMASELLO, 2005).

A partir desse modelo de análise, podemos observar o quão replicáveis são os recursos disponibilizados pelo projeto lexicográfico da FrameNet, de modo a atingir nosso objeto analítico - 0 discurso. Os resultados parciais encontrados que justificam tal assertiva seguem na seção seguinte.

\section{Resultados parciais encontrados:} desvelando o discurso através de rede de frames

As anotações dos corpora fizeram emergir uma rede cujo grande pai é o macroframe Agir_intencionalmente ${ }^{1}$. Tal relação nos mostra, de pronto, um dado analiticamente relevante - o traço de agentividade dos EFs que instanciam a entidade "aluno", como participantes do projeto de dramaturgia desta escola. Este resultado se contrapõe aos achados de pesquisas dos estudos de caso anteriores (FONTES , 2012; TESTA, 2013; LOURES, 2013) em que os alunos foram representados, principalmente, por EFs de caráter passivo. No ambiente em que pesquisamos, portanto, temos um indicador claro do "sucesso" de um projeto: os alunos são agentes, corresponsáveis pelo desenvolvimento do seu processo de aprendizagem. Isso pode ser notado na rede de frames por eles evocada quando perguntados sobre as atividades realizadas na aula de teatro, como se segue:

Relação hierárquica entre frames

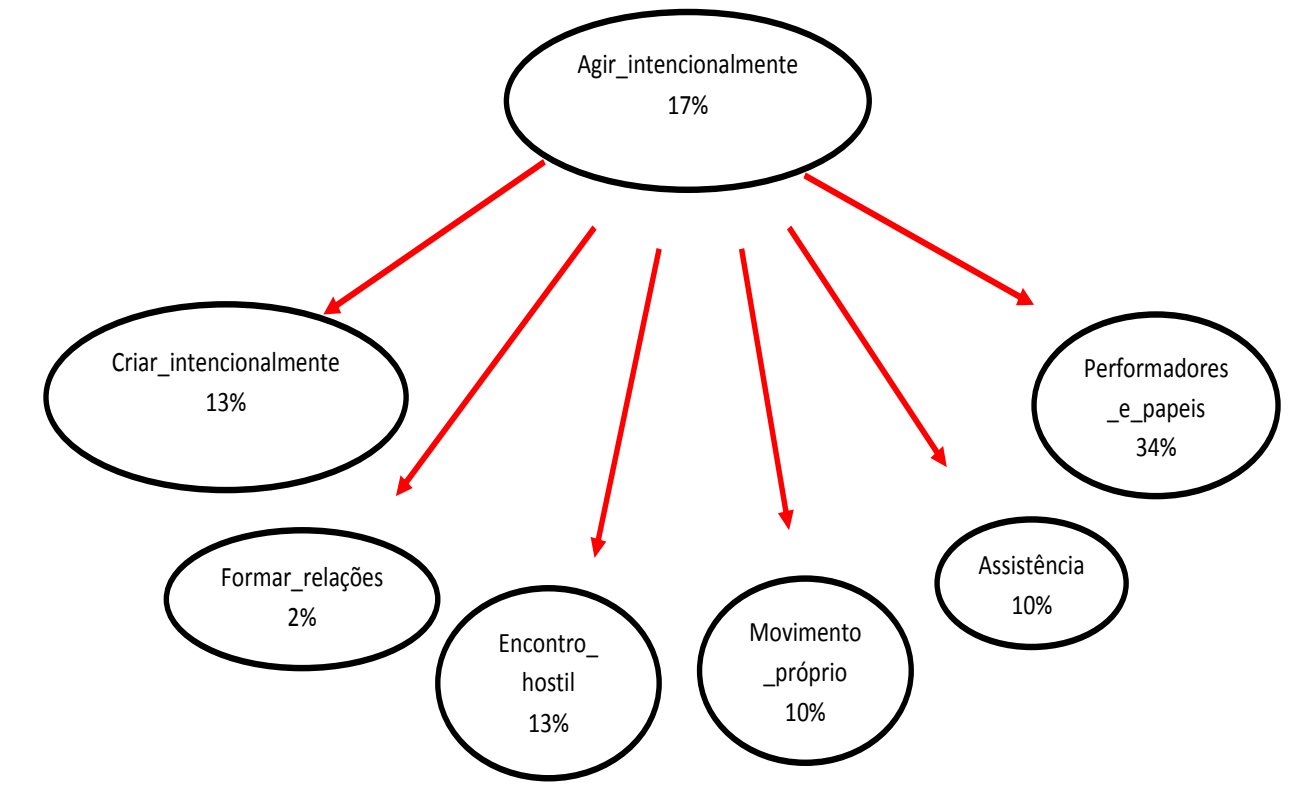

Relação hierárquica entre frames 1

\footnotetext{
1 Devido ao espaço creditado neste artigo, apresentaremos apenas os herdeiros diretos do macroframe Agir_intencionalmente.
} 
Temos, pois, o primeiro mapa emergente da perspectiva instaurada pelos nossos relatores acerca das experiências vividas nas aulas de teatro. Para nós, este é, pois, um mapa inicial do "sucesso" desse projeto de teatro, com pistas bastante contundentes. Uma análise mais minuciosa dessas cenas pode, no entanto, levar-nos a uma compreensão ainda maior. É o que faremos na próxima subseção, buscando examinar as peculiaridades de cada campo conceptual, a fim de compreender como os alunos caracterizam e conceptualizam suas vivências de "sucesso" na aula de teatro.

\subsection{Os frames emergentes}

Todos os frames supracitados têm uma relação de herança com o macroframe Agir_intencionalmente. Essa relação consiste em um dado frame $X$ (filho) ser uma subespecificação de um dado frame $Y$ (mãe), sendo que os Elementos de Frame contidos no frame mãe devem ser os mesmos no frame filho. Nas palavras de Ruppenhofer et al (2010), aquilo que for estritamente verdade a respeito da semântica do frame Mãe deve corresponder a um fato igual ou mais específico sobre o Filho. Isso justifica o fato de todos os demais frames também possuírem um EF agentivo.

Passamos à apresentação sucessiva dos elos desta rede, obedecendo ao critério de maior frequência.

Os relatos acerca de atividades discentes envolvendo agentividade no domínio da dramaturgia são os de maior reincidência (34\%, total de 26 ocorrências), visto que eles são perguntados sobre atividades que realizam durante as aulas de teatro. $A$ maioria das ULs utilizada pelos alunos evoca a cena em que eles estão envolvidos com encenação ou treinamento de alguma peça. $O$ frame Performadores_e_papeis / Performers_and_roles (https://framenet2.icsi.berkeley.edu/fnReports/data/fra melndex.xml?frame=Performers_and_roles), nos dá uma visão mais aprofundada desta cena.

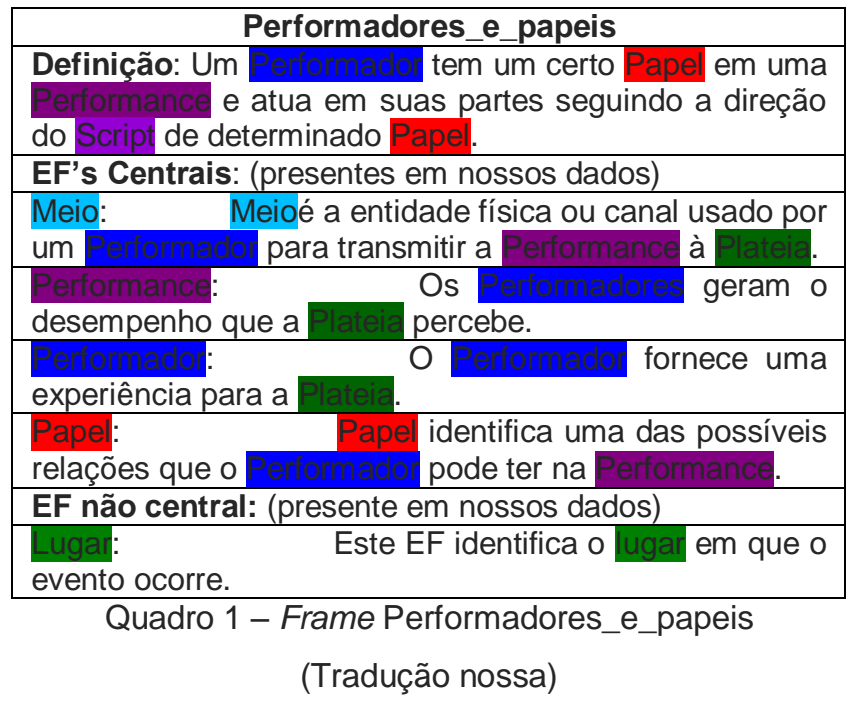

Os eventos descritos que evocam este frame têm como Elemento de Frame mais frequente os EF's centrais (16 ocorrências - 62\%) e Performance (15 ocorrências - 58\%), sendo que o agente de tal cena - o -, em $100 \%$ das vezes, ou seja, nas 16 ocorrências, é desempenhado pelo aluno, isto é, em todas as vezes em que tal frame foi evocado, o aluno se coloca como o agente.

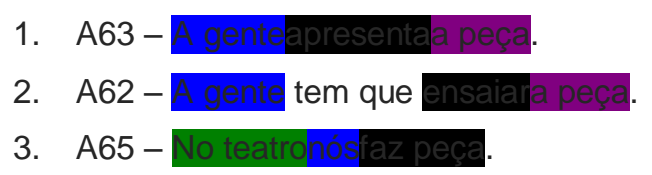

Seguindo a dianteira de Performadores_e_papeis, temos 0 frame Agir_intencionalmente/Intencionally_act (https://framenet2.icsi.berkeley.edu/ fnReports/data/framelndex.xml?frame=Performers an d_roles) com 17\% de frequência (12 ocorrências), cuja descrição é a seguinte:

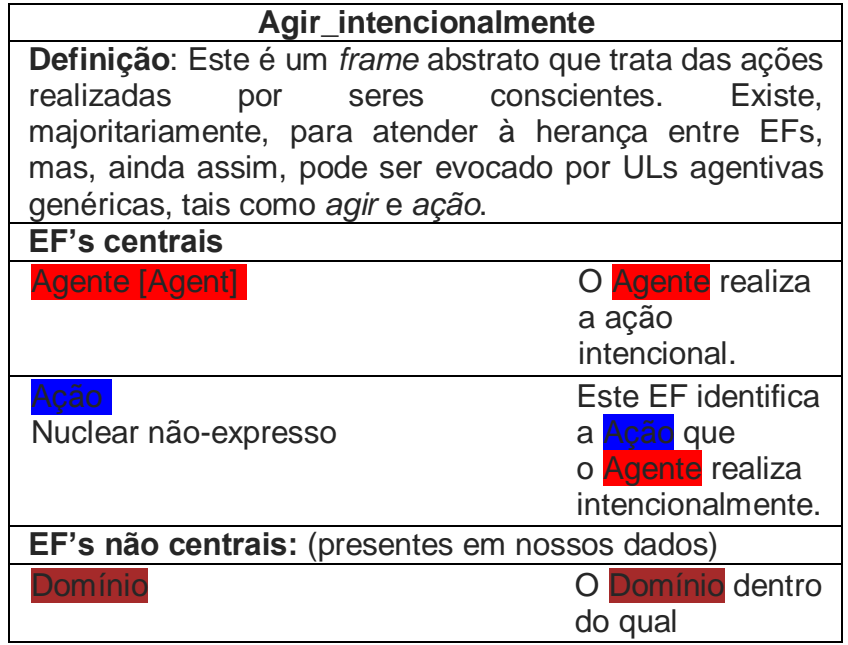




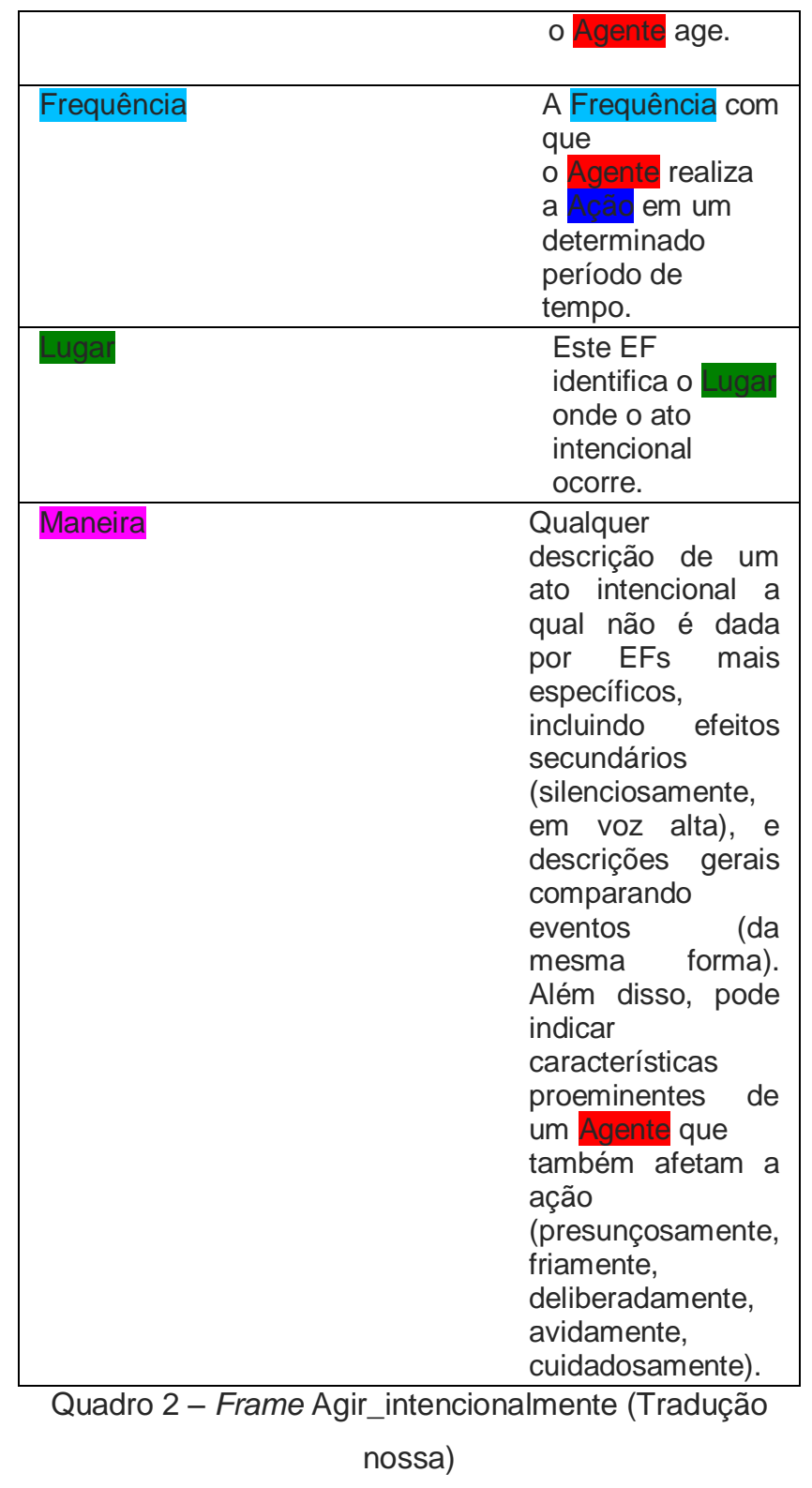

Apesar de se tratar de um frame abstrato, criado com a intenção de tecer relações com outros frames, Agir_intencionalmente pode ser instanciado ao se utilizar ULs genéricas que trazem como fundamento principal a ideia de agentividade, de ação. Novamente, o EF mais reiterado é o de com 92\% das instanciações (11 ocorrências) referindo-se aos alunos entrevistados, na forma de coletivo ou individual. Os outros 8\% (1 ocorrência) referem-se ao professor, às suas ações. Cabe ressaltar que em $100 \%$ das vezes, as atitudes do professor são perspectivadas através de EFs com valores positivos, como pode ser observado no exemplo 7:

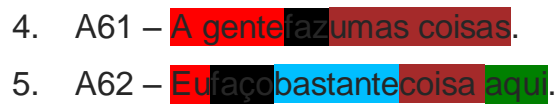

\section{A66 - Eufaçmuitacoisa bacana}

7. A66 - Elefazbastantecoisa assim, boa assim.

Em terceiro lugar, encontra-se o frame Criar_intencionalmente/Intencionally_create

(https://framenet2.icsi.berkeley. edu/fnReports/data/framelndex.xml?frame=Performer s_and_roles) que se refere ao momento em que os agentes da cena estão voltados para atividade de criação. A descrição é a seguinte:

\begin{tabular}{|c|}
\hline Criar_intencionalmente \\
\hline $\begin{array}{l}\text { Definição: O criador cria uma nova uma nova entidade, } \\
\text { a } \\
\text { componentes. }\end{array}$ \\
\hline EF's centrais: \\
\hline Criador: O criador cria a entidade criada. \\
\hline $\begin{array}{l}\text { : Este EF identifica a entidade que o } \\
\text { u intencionalmente. }\end{array}$ \\
\hline EF não central: (presente em nossos dados) \\
\hline $\begin{array}{l}\text { Componentes: Este EF identifica os componentes que } \\
\text { são colocados juntos para formar a }\end{array}$ \\
\hline
\end{tabular}
nossa)

Anotamos neste frame as ULs que se referem a qualquer atividade envolvendo processo de criação. O EF de maior ocorrência (100\% - 9 ocorrências), novamente, é o de agente da cena, o Criador, cujas instanciações referem-se sempre aos alunos, demonstrando o seu protagonismo no processo ensino-aprendizagem.

Outro EF que merece destaque é o de com as seguintes instanciações lexicais e porcentagens: peça $(37,5 \%$ - 3 ocorrências), ideia (37,5\% - 3 ocorrências), história $(12,5 \%$ - 1 ocorrência) e nomes (12,5\% - 1 ocorrência). Isso reflete a dinâmica das aulas de teatro. O professor faz com que os alunos criem aquilo que será encenado. De acordo com nossas observações - participando de reuniões do grupo durante 6 meses - e com a voz discente, nada é dado a priori, o professor atua apenas como mediador do processo inventivo.

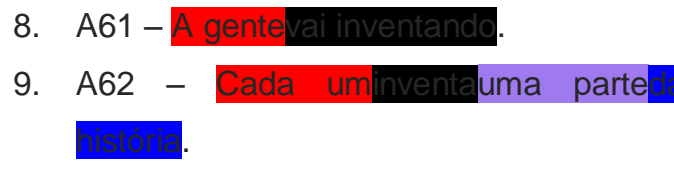

10. A66 - O meu colega sempre

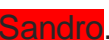


11. A66 - Aí nós tem que

12. A65 - A gente apresenta que

Disputando a posição de terceiro lugar com Criar_intencionalmente, temos um frame que, à primeira vista, opõe-se ao ambiente harmonioso propício ao processo ensino-aprendizagem que estamos traçando. $\mathrm{O}$ frame Encontro_hostil/Hostile_encounter (https://framenet2.icsi.berkeley.edu/ fnReports/data/framelndex.xml?frame=Performers_an d_roles), também com $13 \%$ de frequência (9 ocorrências), encontra-se descrito abaixo:

\section{Encontro_Hostil}

Definição: Este frame é composto por palavras que descrevem cenas de violência entre forças opostas (Lado 1 e Lado 2, coletivamente conceituados como Lados.

\section{EFs Centrais:}

Lado1: Um dos dois participantes em um encontro hostil.

ado2: Um dos dois participantes em um encontro hostil, geralmente o segundo mencionado.

Os lados conjuntamente expressos em um Encontro Hostil. (Não é apresentado em nosso corpus) Os lados conjuntamente expressos em um encontro hostil.

EF Não- central (presente em nossos dados):

Avaliação: Avaliação do evento ocorrido

Quadro 4 - Frame Encontro_hostil (FONTES, 2012)

Através da descrição, percebe-se que este frame não se enquadra como um indicador de sucesso do projeto pesquisado. Entretanto, analisando as sentenças e anotando seus EFs, notamos que em $100 \%$ das vezes em que as ULs evocadoras deste frame aparecem, isto é, em suas nove ocorrências, elas se dão de forma negativa ou com uma avaliação negativa sobre um fato.

13. A64 nada de

14. A66 - Ele tem umas ideias boas. Mas

deia dele é negócio de dar tira, briga. Eu não gosto. Violência eu não gosto.
Essa questão do frame Encontro_hostil ser evocado, principalmente, contendo uma negação à própria UL evocadora ou uma avaliação negativa sobre o caso é analisada a partir dos estudos sobre polaridade (ISRAEL, 2008). A premissa sustentada por ele é de que toda negação pressupõe uma afirmação.

De acordo com o autor, o uso da negação, tanto em termos de discurso quanto em relação ao contexto sintático, é sistemática e significativamente limitado em comparação com a afirmativa. Tal restrição de uso das negativas decorre do fato de estas serem cognitivamente mais complexas que as afirmativas por dependerem da existência cognitiva do que está sendo negado. São, por isso, conceituadas como estruturas marcadas, ao contrário das afirmativas, que são não marcadas.

De acordo com a premissa de Israel (2008), portanto, concluímos que as ações negadas estejam presentes nos ambientes de convívio desses alunos. Como eles negam essas ações no contexto escolar, pressupõe-se que elas sejam vividas em outros locais, como em casa, na rua e em outros espaços. ${ }^{2}$

Empatados em quarto lugar, com $10 \%$ de frequência (7 ocorrências) temos 0 frame de Assistência/Assistance

(https://framenet2.icsi.berkeley.edu/fnReports/data/fra melndex.xml?frame=Performers_and_roles) e o de Movimento_próprio/Self_motion

(https://framenet2.icsi.berkeley.edu/fnReports/data/fra melndex.xml?frame=Performers_and_roles). Os dois dizem respeito às ações que estão presentes durante as aulas de teatro. Abaixo segue a descrição do primeiro frame supracitado.

\begin{tabular}{|l|}
\hline \multicolumn{3}{|c|}{ Assistência } \\
\hline $\begin{array}{l}\text { Definição: Um Auxiliador ajuda uma } \\
\text { permitindo o culminar de um Objetivo que a } \\
\text { tem. }\end{array}$ \\
\hline EF's centrais: (presentes em nossos dados) \\
\hline \multicolumn{2}{c|}{ A recebe a ajuda } \\
de uma ação do Auxiliador. \\
$\begin{array}{l}\text { Auxiliador: O Auxiliador realiza alguma ação para ajudar } \\
\text { a }\end{array}$ \\
\hline $\begin{array}{l}\text { Entidade foca: Este EF identifica a Entidade foca } \\
\text { envolvida para se alcançar o Objetivo. }\end{array}$
\end{tabular}

\footnotetext{
2 Fato que se confirma na entrevista do professor do projeto "Teatro na escola" cuja voz está sendo analisada em outro estudo de caso (MANFILLI-FIORAVANTE, com defesa prevista para 2014)
} 
Objetivo: O desejável estado de coisas que a
do Auxiliador. Quadro 5 - Frame Assistência (Tradução nossa)

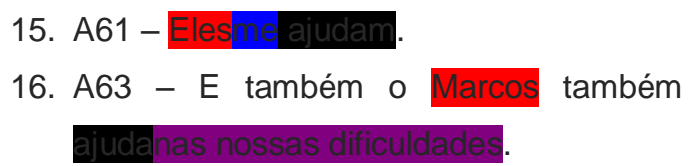

17. A63 - A dificuldade é só ele falar assim: pode me falar que ajudd. [IND] $]^{3}$

18. A64-

O EF Auxiliador é o mais frequente, com 58\% das instanciações, 4 ocorrências, referentes ao professor (exemplos 16,17), 28\% - 2 ocorrências aos alunos (3a pessoa do plural - exemplo 15) e 14\% - 1 ocorrência - à primeira pessoa, como no exemplo 18. Nessa cena evocada, fica claro o ambiente de cooperação presente nas aulas de teatro, tanto na relação entre professor e alunos, quanto entre os discentes. Passemos agora para o frame Movimento_próprio que se refere ao movimento realizado pelos próprios sujeitos.

\begin{tabular}{|l|}
\hline \multicolumn{1}{|c|}{ Movimento_Próprio } \\
Definição: O Sujeito movedor, um ser vivo, o faz sob \\
seu próprio domínio, ao longo do que pode ser descrito \\
como uma sem usar um veículo. \\
EF central: (presente em nosso dado) \\
Sujeito movedor : é o ser vivo que se move sob seu \\
próprio poder. \\
\hline EF's Não centrais: (presentes em nossos dados) \\
\hline Tescricãa: descreve o ator ou a ação. \\
\hline
\end{tabular}
Quadro 6 - Frame Movimento_próprio (FONTES, 2012)

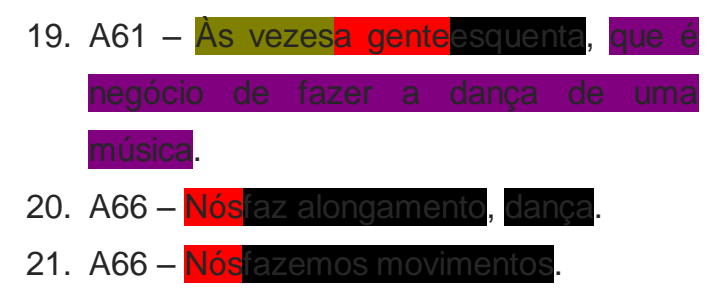

Com relação a esta cena, $100 \%$ do EF Sujeito_movedor (7 ocorrências) refere-se aos próprios alunos inseridos em atividades corporais, como relaxamento antes da encenação, dança, criação de coreografias e outras atividades. Mais uma vez, uma cena que envolve agentividade é evocada por eles.

Por fim, em quinto lugar, temos o frame Formar_relacionamentos/Forming_relationships (https://framenet2.icsi.berkeley. edu/fnReports/data/framelndex.xml?frame=Forming_r elationships), com 3\% das ocorrências (2 ULs anotadas). Segue a sua descrição:

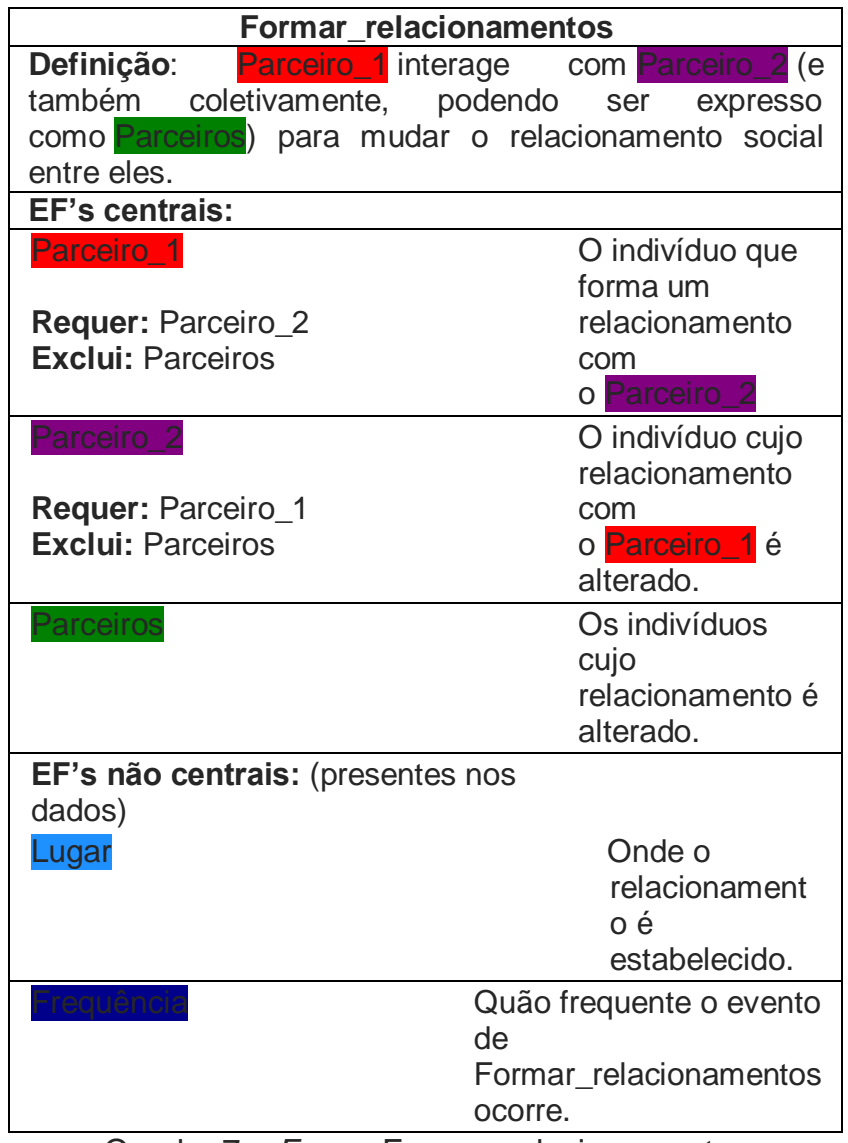

Quadro 7 - Frame Formar_relacionamentos

(Tradução nossa)

22. A64 -Porque na peça assim. A gente conversa.

Este frame foi evocado por apenas um aluno. É interessante notar que esta cena de formar relacionamentos emerge após o mesmo aluno ter evocado o frame de Encontro_hostil, exemplo 23, sugerindo que o mau relacionamento entre os colegas foi superado a partir do momento em que eles ingressaram no grupo de teatro, como pode ser observado no excerto abaixo:

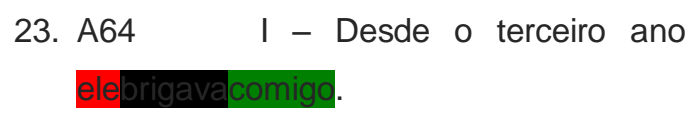


24. A64

$$
\text { E - Ah, é? E aí agora vocês }
$$

estão conversando mais?

25. A64

I - Uhum.

26. A64 $E$ - Por que você acha que vocês tão conversando mais?

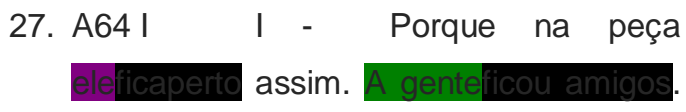

A gente conversa.

Isso comprova que o frame Encontro_hostil emergiu apenas para se referir a um evento passado, já superado, ou para negá-lo. Mais um indicador do sucesso do projeto de teatro na escola, uma vez que a evocação de tal frame, em nenhum contexto, remeteu a um evento de violência, seja ela física ou verbal.

\section{Considerações finais}

Conforme evidenciamos nas seções anteriores, nossa análise preliminar indica que 0 projeto pesquisado não se enquadra ao "mapa da crise" presente na maioria dos contextos escolares desvelados pelos estudos de caso desenvolvidos em nosso macroprojeto (cf. seção 1). Nossas análises preliminares mostram quão favorável é o ambiente das aulas do projeto de Teatro na escola. Todos os frames evocados pelos alunos - a saber Agir_intencionalmente, Performadores_e_papeis, Criar_intencionalmente, Movimento_próprio, Encontro_hostil, Assistência e Formar_relações possuem EF's agentivos, o que demonstra 0 protagonismo discente instaurado na metodologia do professor. O único frame de valor negativo, Encontro_hostil, só foi evocado na forma de negação ou para se falar de um passado já superado.

Tais constatações contribuem com a nossa hipótese de que encontramos, em uma periferia de Juiz de Fora, cercada por um ambiente social bastante desfavorável (tal bairro ocupa a posição de $3^{\circ}$ com maior índice de violência em Juiz de Fora, de acordo com a Secretaria de Estado de Defesa Social) uma escola de sucesso, com práticas educacionais que promovem, por certo, a cidadania de seus alunos.

\section{Referências}

BERNARDO, F.C.Vida escolar - o mapa da crise sob a perspectiva discente. 138f. Dissertação (Mestrado em Linguística) - Programa de Pós-Graduação em Linguística - Faculdade de Letras, Universidade Federal de Juiz de Fora. Juiz de Fora, 2011.

FILLMORE, C. J. Frame semantics. In: The linguistic society of Korea: linguistics in the morning calm. Korea: Hanshin Publishing Company, 1982.

FILLMORE, C.J. Semântica de Frames. Caderno de tradução - Linguística Cognitiva, n. 25, jul/dez 2009.

FILLMORE, C. J; JOHNSON; PETRUCK M. Background to FrameNet. International Journal of Lexicography, v. 16, n. 3. Oxford University Press, 2003.

FILLMORE, C. J. et al. FrameNet in action: the case of attaching. International Journal of Lexicography, v. 16, n. 3. p. 297-332, 2003.

FONTES, Mariana Rocha. Frames e valores: um estudo sobre a normatividade no espaço escolar. 2012. 156f. Dissertação (Mestrado em Linguística) Universidade Federal de Juiz de Fora. Juiz de Fora, 2012.

ISRAEL, Michael. The pragmatics of polarity. In: The handbook of pragmatics. HORN, L. R.; WARD, G. (Eds.). Oxford, UK: Blackwell Publishing Ltd, 2008.

LIMA, F.R.O. A perspectiva discente do frame aula. 2009, 144 f. Dissertação (Mestrado em Linguística) Programa de Pós-Graduação em Linguística Faculdade de Letras, Universidade Federal de Juiz de Fora. Juiz de Fora, 2009.

RUPPENHOFER, J. et al. FrameNet II: extended theory and practice.Versão 14 set. 2010. Disponível em: <http://framenet.icsi.berkeley.edu/>. Acesso em: 1 jun. 2011. 